Гарипова Г. Т.

\begin{abstract}
Аннотация. Цель исследования - определить специфику художественного проектирования миромодели по принципу антибартовской формулы «мир не текст», лежащей в основе дистопии «посткнижного мира» в романе В. Сорокина «Манарага». Научная новизна исследования заключается в том, что впервые проводится интегральный анализ культурфилософских, социологических, художественных составляющих миромодели «посткнижного мира», инициирующих эстетическую футуромодель «цивилизаторского проекта» через провиденцию культурологической антиутопии В. Сорокина. Полученные результаты показали, что гипертекстовая семантика «возможных миров» представлена в романе через интертексты семиотического пространства «библиоклазма», имплицитно содержащие «скрытую логику» разрушения «культурного человечества».
\end{abstract}

\title{
Artistic Realization of "Post-Literary" Cultural and Philosophical Models in Modern Literature (by the Material of V. Sorokin's Novel "Manaraga")
}

\author{
Garipova G. T.
}

\begin{abstract}
The paper aims to reveal specificity of artistic realization of the "anti-Barth" world model based on the formula "the world isn't a text" in V. Sorokin's novel "Manaraga". Scientific originality of the study lies in the fact that the researcher for the first time provides a comprehensive analysis of cultural and philosophical, sociological, artistic components of the "post-literary" world model constituting architectonics of the futurological "civilizing project" in V. Sorokin's culturological anti-utopia. The findings indicate that in V. Sorokin's novel, hyper-textual semantics of "alleged worlds" is represented through inter-texts of the semiotic space "biblioclasm", which implicitly contain logic of destruction of the "civilized mankind".
\end{abstract}

\section{Введение}

Актуальность темы статьи обусловлена интересом современного литературоведения к решению проблемы идентификации принципов художественного конструирования «возможных миров», а также к аналитическому исследованию современных авторских экспериментальных эстетических практик миромоделирования. Вопросы дефиниции мифопоэтических констант в авторских трансперсональных миромоделях являются научно значимыми и перспективными исследовательскими направлениями. Актуальность исследования также связана с выявлением в романе современного прозаика В. Сорокина «Манарага» интертекстуальных соотнесений постмодернистской протоформулы «мир как текст» с антиутопическими моделями «библиоклазма», соотносимых с культурфилософскими метамифами. Внимание к роману В. Сорокина во многом обусловлено современной тенденцией трансформации антиутопии в дистопию и ретротопию. Данное исследование актуализирует проблему выявления гипертекстового механизма внутрижанровой трансформации, что открывает возможности для идентификации скрытых «горизонтов ожидания» в развитии жанра антиутопии, а также способствует дефиниции его миромоделирующих функций.

Цель исследования достигается решением ряда задач: проанализировать гипертекстовую стратегию проектирования миромодели «посткнижного мира» в романе В. Сорокина «Манарага», реализуемой через 
моделирование «возможного мира» посредством «сознательного» авторского мифообразопостроения; идентифицировать ключевые смысловые интертексты; определить особенности дистопийных и ретротопийных критериев романа.

В работе используются следующие методы исследования: интертекстуальный анализ, мифопоэтический анализ, принципы рецептивного исследования, а также метод герменевтики (с акцентом на интерпретации художественного текста в контексте культурфилософских теорий «библиоклазма»).

Теоретической базой исследования послужили труды В. Хализева [14], Ю. Лотмана [8], 3. Баумана [1], Е. Бернштейна [2], Э. Шафранской [15], Л. Данилкина [5], О. Турышевой [13]. Так, положения В. Хализева о романных «мироподобных» структурах и о ценностных координатах мироподобия художественной модели мира, позволяющие констатировать художественную миромодель как «аналог целостного бытия» [14, с. 155], могут позиционироваться нами как методологическое основание проведенного анализа. Это приводит к переориентации традиционного «мироприемлющего начала» романных миромоделей на художественное миростроительство или миромоделирование как стратегии художественного текстообразования. Исследователь О. Н. Турышева выделяет в качестве смысловых претекстов сюжета о сжигании книг целый ряд романов, разрабатывающих тему библиоклазма: «Это представление о книге как источнике зла и угрозы, или разочарование в книжных иллюзиях, или требования трагических обстоятельств. Данная типология используется для обоснования оригинальности изобретенного В. Сорокиным мотива» [13, с. 141].

Практическая значимость исследования определяется возможностями использования материалов статьи в курсах по новейшей отечественной литературе, а также в междисциплинарных исследованиях проблемы миромоделирования «возможных миров».

Наиболее активно модели «возможных миров» представлены в направлениях и явлениях, связанных не с миметическими установками (отражение действительности в тексте), а с антимиметическими концепциями порождения мира «символического», в модернизме и постмодернизме представленного формулой Р. Барта «мир как текст». Так, в неклассических моделях романа эстетическая интерференция текстовой реальности и художественной картины онто-мира инициирует в художественном произведении ее образную аллегорезу «мир как книга». В романе В. Сорокина «Манарага» образная миромодель представлена в эстетическом процессе прототипирования антибартовской формулы «мир не текст» через провиденцию культурологической антиутопии. Образ «книжного мира» уходит в прошлое, проецируется в метакультурный миф, цитация которого превращается в ретро-игру с традиционной культурой. Постапокалипсис «мира как текста» определяет суть дистопии В. Сорокина «Манарага».

\section{Гипертекстовые стратегии проектирования миромодели «посткнижного мира» в романе В. Сорокина «Манарага»}

Роман В. Сорокина не создает антитезис к утопии «мира как текста», он констатирует антиутопию постсовременного мира, в котором «рукописи горят»- в прямом и переносном смысле. Предметный план миромоделирующей метафорики контекстуально представлен открытым интертекстом сгоревшего второго тома «Мертвых душ» Н. Гоголя, сюжетной метафикцией горящего романа в романе «Мастер и Маргарита» М. Булгакова, историями с полной версией «Русского Трианона» А. Ахматовой и романа Б. Пастернака «Три имени» и т.д. Образный план проявляется, на наш взгляд, в ряде исторических библиоклазмов прошлого, но особенно в сюжетизации знаменитой метафоры китайской историографии, обозначающей события 213-12 гг. до н.э. «Сожжение книг и погребение книжников». Непрямая архитектоника смысла в «Манараге» выстраивается в системе «цитирующего» гипертекста, развернутого на всех уровнях постмодернистских форм эклектики заимствования, реинтерпретация, ремейк, мозаичность, бриколлажность, фенотекст и т.д. Диссипативная бесконечность самопорождающихся смыслов и интерпретационных саморефлексий детерминирована ризоматической схемой миромодели культурологического «удела человеческого», постулируемого в системе нелинейных передвижений героя романа Гезы в «посткнижном» мире. Движение по гипер-лабиринту осуществляется в системе потенциальных в своей бесконечности смыслов, имплицитно содержащих «скрытую логику» разрушения историко-литературной закономерности развития «культурного человечества». Мотив «горящих рукописей» апперципирует в романе Сорокина дистопийные и ретротопийные смыслы культурного постапокалипсиса для обозначения модели «культурного удела человеческого» (определение Б. Паскаля [7, с. 150]) пост- и постпостмодернистской современности. Семиотическая архитектоника миромодели в «Манараге» складывается из скрытых смыслов, закодированных в «сжигаемых» книгах, эстетический шифр которых «цитирует» культуру прошлого, развернутую как утопический код для антиутопического «мира без текста». Трансформация в дистопию осуществляется на уровне «возможной миро-семантики» «культурного удела человеческого» - все книги приговорены к сожжению и ждт своей очереди. Ценностные смыслы этих книг девальвируются «сжиганием» в современном мире, обреченном на «трагедию смыслоутраты» (Ю. Давыдов) [4, с. 48]. Акцентация на конкретном обозначении «жажды» сжечь ту или иную книгу определенного издания позволяет говорить о культурно-аксиологической девальвации историко-литературного контекста «книжного мира», порой концептуально значимого для идентификации «темных мест», проецируемых в романе смысловой матрицей «горящей рукописи». 


\section{Принципы построения смысловых интертекстов}

Модель «посткнижного мира» обозначает не жизненный мир, но эпистемологический, герменевтическая модель которого складывается из смыслопорождаемых контекстов «темных мест», не раскрываемых и практически не интерпретируемых автором и героями, но семантически разворачиваемыми воспринимающим сознанием читателя. Гипертекст Сорокина есть пропозиция к «возможному» смысловому миру читателя через игровую логику «двойной цитации»: «Вечер: шашлык из осетрины на “Идиоте”. Роман полноценный, второго среднего веса, 720 граммов, 509 страниц, бумага веленевая, цельнотканевый коленкоровый переплет. Вполне хватило на восемь шампуров. Как и было обговорено, клиент + семеро гостей восседали вокруг жаровни. Естественно, не только чтобы убедиться, что я жгу именно первое издание, книгу за 8700 фунтов, а не подменил ее каким-нибудь северным детективом XXI века про сто пятьдесят оттенков посредственности. Они хотели искусства. И получили его. Все, все соответствовало. Я был на высоте. Хотя только book'n'griller знает, сколько в его работе подводных камней. Это - наша внутренняя кухня. Романы, как известно, печатались на разной бумаге. И гореть она может по-разному. <...> ...книга должна быть яркой: пылать и поражать. <...> Переплет, каптал, коленкор, картон, марлевые клапаны, пеньковый шнур, закладки, казеиновый клей, засушенные цветочки, книжные вши, клопы или тараканы в корешке - все это скрытые угрозы. Их необходимо учитывать» [11].

Важное значение, на наш взгляд, приобретает кодировка инсектного кода - угроза формата «вши, клопы или тараканы в корешке» выводит читателя в семиотическое «инсектное» поле русской литературы - это и «блоха» Лескова, «таракан» Чуковского, «клоп» Маяковского и т.д. Но самым знаковым «возможным» иномирным смыслом становится соотнесение угрозы «вшей... в корешке» с частью «Как вщей выводить» «Немемуаров» Ю. Лотмана. Гибридная нарративная стратегия устного и литературного письма акцентирует претекст фольклорной модели «некнижного мира». Угроза возврата в архаику «докнижного мира» актуализирует, с одной стороны, традицию уже существовавшего прошлого, с другой - вводит семантическое соотнесение создаваемого мирообраза со значением «война». Лотман пишет, что тему «вшей» «не обошел никто, кто относительно правдиво писал о войне, от Барбюса до Гашека», поскольку «вошь - частично запрещенная тема, она касается “той” стороны военного быта» [8, с. 23]. Русские солдаты придумали способ борьбы - выпаривание вшей. И Лотман рассказывает о случае, когда в процессе выпаривания сгорает вся одежда. Смысл угрозы Сорокина в лотмановском «цитирующем» контексте очевиден - в цивилизационной войне «книжного» и «человеческого» миров второй может и сгореть.

Е. Бернштейн, рассматривая мотив «вшей», выявляет в инсектной символике книги Л. Гинзбург «День Оттера» знак «экзистенциального отчаяния» [2]: «Вши внушали иррациональный ужас. Их склизкая прозрачность была воплощением низшей неорганизованной материи, грозящей вновь поглотить цивилизованного человека. <..> Хуже всего в них была неподвижность, с которой они сидели в складке рубашки, на сгибе воротника. Они не боялись, не убегали, их нельзя было вспугнуть, и они позволяли давить себя без сопротивления. Но в этом-то и был самый ужас - никакие проявления человеческой жизни их не касались» [3, с. 215].

Найденный Бернштейном у Гинзбург образ «сознания, наблюдающего свой распад» («Обозначая собой стадии телесного умирания, вши будят у рассказчика кошмарное чувство отчуждения собственного гибнущего тела от разрушающегося сознания» [2]), наложенный на смыслы лотмановского знака крушения цивилизации, «цитируются» в семиотическом пространстве инсектного кода и «Манараги», раскрывая смыслы главной угрозы рушащегося «книжного мира»- эсхатологического конца человеческой цивилизации. «Умная блоха» в голове повара, готовящего на горящих книгах - экстраполяция цифрового искусственного интеллекта в самонаблюдающее самораспад сознание человека - одна из реальных социогуманитарных проблем постэкзистенциальной современности. «Реквием по бумажной книге» на самом деле лишь претекст к реквиему по человечеству, променявшему культуру «мир как книга» на виртуальность «цифрового мира».

\section{Специфика семантизации дистопийных и ретротопийных критериев}

В романе Сорокина научное внедрение «умной блохи» (формат искусственного интеллекта) в сознание, искусство игры book'n'griller, его чувственное восприятие «сгорающих» книг становятся конструктами мирагипертекста, философия которого, на наш взгляд, связана с идеей возможного построения человеком новых миров (или новых искусственных культур) в процессе культурологической символизации «книжной» цитации. Сорокин определяет постмодернистский гипертекст (бытующий по условиям «мира как текста, уходящего в прошлое») как способ цитирования гиперреальности «мира не текста». «Манарага» Сорокина перерастает из дистопии в ретротопию, определяемую социологом 3. Бауманом как состояние общества, прощающегося со своим прошлым [1].

На наш взгляд, культурологическая инженерия модели ретротопического мира у Сорокина структурируется в системе философии «Книги для сожжения» китайского ученого нонконформиста Ли Чжи (1527-1602). В «Манараге» дается реконструкция ее историографических смыслов, а в семиотическом поле представлена экзегеза сюжета «библиотечных катастроф», в основе которых лежит идея социально-культурной амнезии. В рецептивном интертекстуальном поле «Манараги» обнаруживается экзегеза таких философских положений «Книги для сожжения», как смысловая иллюзорность культуры и туманность социально-общественных институтов, признание ценности таланта и необходимости его своевременного распознавания и использования, 
рассмотрение плотских потребностей как части Дао-пути совершенномудрого человека и т.д. В романе Сорокина идея Ли Чжи о том, что сознанием управляет все инстинктивное и здравомысленное, а чистая «правда мира воплощается в одежде и еде», наложенная на актуализированную современной масс-культурой метафору «съедобная литература» и провиденцию метаморфной метафоры «горящих книг» в другом романе писателя «День опричника», создает смысловую архитектонику («Это симбиоз физиологии, шоу и моды. Занятие book'n'grill - опасная, запретная вещь, в результате которой раритет сгорает навсегда. Он отдает свою энергию блюду, а оно насыщает клиента. В общем, Наташа, речь идет о съедобной литературе!» [11]), обозначенную трудом Жан-Клод Карьера и Умберто Эко «Не надейтесь избавиться от книг!»: «Цель не в том, чтобы посмотреть во что бы то ни стало, или прочесть во что бы то ни стало, а в том, чтобы знать, что с этим делать и как извлечь из этого пищу для размышлений, которой хватило бы надолго» [6].

Сорокин находит ответ на вопрос «что с этим делать»- использовать книги в качестве топлива для поиска размышлений. Однако автор понятие «размышления» сводит к понятию «чувствование-наслаждение», на наш взгляд, соотносимое с третьим модернистским принципом по Д. Мережковскому: «расширение художественной впечатлительности». Именно «жадность к неиспытанному, погоня за неуловимыми оттенками, за темным и бессознательным в нашей чувствительности» [10, с. 170] становится той самой «пищей для размышления» в «Манараге», добыванием которой через сожжение книг занимается book'n'griller и его клиенты. Проявление подобной «чувствительности» как некой потребности бессознательного в романе представлено в разных формах - жажда творчества, проявляющаяся через эпидейктическую речь ряда героев, сопровождающая «горение книги», жажда власти, чревоугодие, похоть и т.д. Извлекается все, что может быть обозначено понятием «страсть». Но это не высшее проявление чувств человека, в романе это антитеза «размышлению» как формы культурной сознательности: «С тех пор как человечество перестало печатать книги и навсегда сделало лучшие из них музейными экспонатами, book'n'grill появился на свет. Люди всегда тянутся к запретному плоду. Девяносто процентов отпечатанных человечеством книг были сданы в утиль или просто выброшены на помойки, чтобы не занимали пространство в квартирах. А вот оставшиеся десять, осевшие в музеях и библиотеках, вдохновили лучшую часть человечества на удивительную страсть. Первый стейк был зажарен двенадцать лет назад в Лондоне на пламени первого издания “Поминок по Финнегану”, выкраденного из Британского музея. Его приготовили и съели четверо великих мужей - психоаналитик, флорист, биржевой брокер и контрфаготист. Так родился book'n'grill. Это положило начало великой страсти, ставшей за эти стремительные годы великой традицией...» [11].

Так, характерный для экспериментального романа писателя-модерниста Д. Джойса «Поминки по Финнегану» мономиф «вечного возвращения» и антропософский тип «героя пути» предопределяют сюжетносмысловую архитектонику «Манараги» - сжигая книги, главный герой все время возвращается к культурным смыслам, обозначенным смысловым ядром сжигаемых книг. Из одного культурного мифа герой и повествователь Геза переходит в другой миф, следуя профессиональному долгу, таланту и, главное, чувствам и страстям, которые в романе подменяют черты характера и определяются как психологические составляющие «смыслового распада» культурной памяти человека.

\section{Моделирование «возможного мира» посредством авторской ретроспекции «безумного сознания» «Книги для сожжения» Ли Чжи}

Таким образом, модель горящего «книжного мира» инициирована в том числе и философско-психологической проекцией онто-антропологической ретроспекции еще одной идеи «безумного сознания» «Книги для сожжения» Ли Чжи. Философ акцентировал причину иллюзорности культуры и общественных институтов через понятие «действие сознания», невозможность осознания которого в себе оборачивается трагедией «неосознанного сознания», ведущего к потере традиции и исконной правды. Сорокин вскрывает причины современного экзистенциального кризиса, связанного с рождением новой культурогенной традицией трансформации книжной «осознанной» культуры в информационную «потребляемую» культуру. Уход из реальности в информационный мир (медиатор перехода - умная блоха), встраиваемый в сознание героя и постепенно подменяющий его, и онейросферу психоделического «неосознанного сознания» формирует «безумное сознание» (Ли Чжи), неспособное, по мысли В. В. Малявина, «вернуть жизнь общества к её исконной правде» [9, с. 135]. «Герой пути» Геза не склонен к духовному движению к открытию истины, его социальная роль несостоятельна, духовное предназначение подменено плотскими желаниями. Инспирация «книжного мира», глубоко переживаемая в опыте «сжигания книг» героем, могла бы привести его к духовному «действию сознания», преодолевающему энтропийное влияние посткультуры на эмпирическое сознание человека. Геза был способен в силу своего творческого таланта к «совершенномудрию», но для него акт сжигания книг каждый раз превращался в акт самосожжения, ибо почерпнутые и понятые смыслы растворялись в «игровом сознании» как мнимые, но не истинные.

Роман заканчивается сценой «плотского безумия», которое распавшееся сознание Гезы воспринимает апокалипсически: «Шапочка лопнула. И вместе с ней - весь мой прошлый мир. Клочья его летят на каменный пол» [11]. Акцентация на плотских желаниях героя Гезы не случайна и созвучна с идеей Ли Чжи о том, что полноправность плотских потребностей есть часть Дао-пути человека, а уподобление утоления физического голода утолению голода духовного позволяет реализовать потенциал совершенномудрого в каждой личности.

Подчеркнутая Сорокиным игровая природа саморазрушающейся традиции «манараговской» социологии «Опытный мастер обязан просчитать весь процесс как шахматную партию и хладнокровно балансировать 
над пропастью» [Там же] - есть, в первую очередь, не эсхатология «книжного мира», а апокалипсис «культурного сознания» человеческого общества, зарождающегося уже сегодня в недрах информационного мира, постепенно заменяющего/вытесняющего искусственным интеллектом живое сознание совершенномудрого.

Таким образом онтологические, культурологические и экзистенциальные смыслы романа Сорокина «Манарага» выстраивают авторскую концепцию, которая может быть обозначена одновременно как социология культуры и культура постсовременного социомира. Критик Л. Данилкин усматривает в «Манараге» и некий политический памфлет на эту самую культуру: “Манарага” - роман о тех, кто обладает привилегией формировать литературный канон... “вопрос о книгах” - вопрос не эстетический, а политический... И поскольку Сорокин, всю жизнь именно с этим феноменом работавший, прекрасно знает это - в литературоцентричной России тот, кто определяет и контролирует литературный канон, контролирует также и цайт-гайст, престижность или маргинальность политических практик, моральные критерии, по которым оцениваются внелитературные персонажи. <...> Литература - это власть, вот что важно; и статус - тот или иной - книгам присваивают “жрецы”, они договариваются, кого брать в будущее» [5].

Именно в таком семиотически полизначном понимании романа содержится ответ на вопрос о смысле коммерциализации книжной культуры в современном мире, когда формируемый социологически премиальный вектор провиденциально определяет будущий облик человека и мира. «Книги для сожжения» сегодня это вся традиционная культура, не внедряющаяся в сознание подобно информационной «умной блохе», а заставляющая «осознавать сознание», думать, развиваться, совершенствоваться. По сути в символической форме «Манараги» Сорокина реципирует социологический библеоклазм, предсказанный в свое время Рэем Брэдбери в образе диктаторского общества, в котором все книги подлежат сожжению, в антиутопии «451 градус по Фаренгейту».

Рассматривая на примере другого провиденциального романа В. Сорокина «Теллурия» новую фазу постпостколониального дискурса, Э. Ф. Шафранская пишет: «Что же будет потом, когда постколониальность уйдет в историю? Возможно, постпостколониальность. Собственно, постпостколониальная фаза уже существует: в романе-антиутопии Владимира Сорокина “Теллурия” (2013) речь идет о середине XXI века, рассказчик делает экскурс в историю, где дореволюционная Россия видится страной с неприлично безразмерной колониальной географией [12, с. 15]. <..> Это - из области художественных пророчеств...» [15, с. 223]. В романе В. Сорокина «Манарага» образ «некнижного мира» также может служить «символическим артефактом “цивилизаторского проекта”» [Там же], провиденциально означающего социоэнтропию постпостколониального мира, в котором «рукописи горят».

\section{Заключение}

В ходе проведенного исследования можно сделать выводы о том, что 1) гипертекстовая стратегия проектирования антиутопической миромодели «библиоклазма» в романе В. Сорокина «Манарага» реализуется через моделирование «возможного мира» посредством проектирования «цивилизаторского проекта» посткнижного мира; 2) ключевые смысловые интертексты романа соотносятся с «инсектными» мифокодами, с антиформулой библиоклазма «рукописи не горят», с мифологемой «безумного сознания» (из «Книги для сожжения» Ли Чжи); 3) особенности дистопийных и ретротопийных критериев романа связаны с тем, что в нем представлена модель нарождающейся новой культурогенной традиции перерастания книжной «осознанной» культуры в информационную «потребляемую» культуру, содержащую «скрытую логику» разрушения модели развития литературоцентричного общества.

Таким образом, художественная миромодель культурфилософского «библиоклазма», представленная в романе В. Сорокина «Манарага», при всей парадоксальности фантасмагорической модели «конца света», укладывается в общую антиутопическую тенденцию начала XX века: если художественное проектирование идеалистических миромоделей начала XX века строилось по принципу инициации «возможной утопии» будущего мира, связанного с ожиданием прихода Мессии - духовного Спасителя человечества, - то современная литература проецирует антиутопическую футуромодель (с вариантами дистопии и ретротопии), провиденциально связанную с ожиданием Апокалипсиса. Перспектива дальнейшего исследования может быть определена анализом миромодели современного библиоклазма с позиции социологической провиденции, детерминированной в понимании В. Сорокина культурой «посткнижного» Апокалипсиса.

\section{Список источников}

1. Бауман 3. Ретротопия [Электронный ресурс] // Мониторинг общественного мнения: экономические и социальные перемены. 2018. № 6. C. 435-442. URL: https://monitoringjournal.ru/index.php/monitoring/article/ view/554 (дата обращения: 10.11.2020).

2. Бернштейн Е. Семиотика одного мотива: вошь (Pediculus humanus corporis) в «Не-мемуарах» Лотмана и в русской военной прозе [Электронный ресурс] // Неприкосновенный запас. 2016. № 4. URL: https://magazines. gorky.media/nz/2016/4/semiotika-odnogo-motiva-vosh-pediculus-humanus-corporis-v-ne-memuarah-lotmanai-v-russkoj-voennoj-proze.html (дата обращения: 12.10.2020). 
3. Гинзбург Л. Я. Проходящие характеры: проза военных лет, записки блокадного человека. М.: Новое издво, 2011.598 с.

4. Давыдов Ю. Н. Этика любви и метафизика своеволия: проблемы нравственной философии. М.: Молодая гвардия, 1982. 287 с.

5. Данилкин Л. О чем на самом деле «Манарага» Владимира Сорокина [Электронный ресурс] // Aфиша Daily. 2017. 14 марта. URL: https://daily.afisha.ru/brain/4792-o-chem-na-samom-dele-manaraga-vladimira-sorokinaobyasnyaet-lev-danilkin/ (дата обращения: 31.01.2020).

6. Карьер Ж.-К., Эко У. Не надейтесь избавиться от книг! [Электронный ресурс]. URL: https://www.litmir.me/ $\mathrm{br} / \mathrm{?b}=146274 \& \mathrm{p}=1$ (дата обращения: 23.10.2020).

7. Ларошфуко Ф. дэ. Максимы. Паскаль Б. Мысли. Лабрюйер Ж. дэ. Характеры. М.: Худ. лит-ра, 1974. 541 с.

8. Лотман Ю. М. Не-мемуары // Лотмановский сборник / сост. Е. В. Пермяков. М.: Иц-Гарант, 1995. С. 5-53.

9. Малявин В. В. Сумерки Дао. Культура Китая на пороге Нового времени. М.: Дизайн. Информация. Картография; АСТ; Астрель, 2003. 436 с.

10. Мережковский Д. С. Эстетика и критика: в 2-х т. М. - Х.: Искусство; Фолио, 1994. Т. 1. 669 с.

11. Сорокин В. Манарага [Электронный ресурс]: роман. URL: https://knigogid.ru/books/814721-manaraga/toread (дата обращения: 10.11.2020).

12. Сорокин В. Теллурия: роман. М.: АСТ; Corpus, 2013. 448 с.

13. Турышева О. Н. Сожжение книг: новая семантика старого мотива (на материале романа В. Сорокина «Манарага») // Филологический класс. 2018. № 2 (52). С. 141-145.

14. Хализев В. Е. Теория литературы. М.: Высшая школа, 1999. 398 с.

15. Шафранская Э. Ф. Фазы колониального дискурса в русской прозе о Туркестане // Филология и культура. 2017. № 2 (48). C. 218-224.

\section{Информация об авторах | Author information}

RU Гарипова Гульчира Талгатовна ${ }^{1}$, к. филол. н., доц.

${ }^{1}$ Владимирский государственный университет имени А. Г. и Н. Г. Столетовых

EN Garipova Gulchira Talgatovna ${ }^{1}, \mathrm{PhD}$

${ }^{1}$ Vladimir State University named after A. G. and N. G. Stoletovs

1 gulyagaripova1@rambler.ru

\section{Информация о статье | About this article}

Дата поступления рукописи (received): 15.12.2020; опубликовано (published): 09.04.2021.

Ключевые слова (keywords): миромоделирование; В. Сорокин; возможный мир; антиутопия; библиоклазм; world modelling; V. Sorokin; alleged world; anti-utopia; biblioclasm. 